\title{
The chemistry and synthesis of 1H-indole-2,3-dione (Isatin) and its derivatives
}

\author{
Ratnamala P. Sonawane*, Rahul R. Tripathi \\ Institute of Science, 15, Madam Cama Road, Fort, Mumbai - 400032, Maharashtra, India \\ *E-mail address: ratnasonawane@yahoo.in
}

\begin{abstract}
Isatins are synthetically versatile substrates, where they can be used for the synthesis of a large variety of heterocyclic compounds. In this, a convenient method has been developed for the conversion of Indoles into Isatins and some heterocyclic derivative were synthesised such as 5-nitro1H-indole-2,3-dione, 2-methylquinoline-4-carboxylic acid which may be used as raw material for drug synthesis. The general process utilizes the effective method for synthesis of Isatin from Indole is bromination and oxidation with an N-bromosuccinimide-dimethyl sulfoxide reagent. The nitration of Isatin at $\mathrm{C}-5$ takes place by using $\mathrm{KNO}_{3}$, conc. $\mathrm{H}_{2} \mathrm{SO}_{4}$, 2-methylquinoline-4-caboxylic acid are usually obtained from pfitzinger reaction.
\end{abstract}

Keyword: Indole; Isatin; NBS-DMSO; Pfitzinger reaction; 5-nitro-1H-indole-2,3-dione; 2methylquinoline-4-carboxylic acid

\section{INTRODUCTION}

Isatins (1H-indole-2,3-dione) are synthetically versatile substrates, where they can be used for the synthesis of a large variety of heterocyclic compounds, such as indoles and quinolines, and as raw material for drug synthesis ${ }^{1-4,8-9}$. The general process utilizes the effective method for synthesis of Isatin from Indole is bromination and oxidation with an Nbromosuccinimide- dimethyl sulfoxide reagent. The nitration of Isatin at C-5 takes place by using $\mathrm{KNO}_{3}$, con. $\mathrm{H}_{2} \mathrm{SO}_{4}{ }^{20-25}$ 2- Methylquinoline-4-caboxylic acid are usually obtained from pfitzinger reaction.

A spiro compound N,N'-(2-oxo-3'H-spiro[indoline-3,2'-[1,3,4]thiadiazole]-3'5'diyl)diacetamide were synthesise by refluxing Isatin and thiosemicarbazone in ethanol and then on heating with acetic anhydride underwent to cyclization into intermediate that on acetylation of the $\mathrm{NH}$ and $\mathrm{NH}_{2}$ groups afforded the spiro compound. Isatins have also been found in mammalian tissue and their function as a modulator of biochemical processes has been the subject of several discussions ${ }^{11}$.

The advances in the use of isatins for organic synthesis during the last twenty-five years, as well as a survey of its biological and pharmacological properties are reported in this review and in the accompanying supplementary information ${ }^{6}$. Isatin $(1 \mathrm{H}$-indole-2,3-dione, Figure 1) was first obtainedby Erdman and Laurent in 1841 as a product from theoxidation of 
indigo by nitric and chromic acids ${ }^{12}$. Isatin (1H-indole-2,3-dione), was first obtained by Erdman and Laurent in 1841 as a product from theoxidation of indigo by nitric and chromic acids. The synthetic versatility of isatin has led to the extensive use of this compound in organic synthesis. Three reviews have been published regarding the chemistry of this compound: the first by Sumpter, in 1954, a second by Popp in 1975 and the third on the utility of isatin as a precursor for the synthesis of other heterocyclic compounds ${ }^{10}$. The synthetic versatility of isatin has stemmed from the interest in the biological and pharmacological properties of its derivatives. These properties are more fully detailed in the supplementary material.In nature, isatin is found in plants of the genus Isatis, in Calanthe discolor LINDL. and in Couroupita guianensis Aubl., and has also been found as a component of the secretion from the parotid gland of Bufo frogs, and in humans as it is a metabolic derivative of adrenaline ${ }^{12-15}$.

Substituted isatins are also found in plants, for example the melosatin alkaloids (methoxy phenylpentyl isatins)obtained from the Caribbean tumorigenic plant Melochia tomentosa as well as from fungi: 6-(3'-methylbuten-2'-yl)isatin was isolated from Streptomyces albus and 5-(3'-methylbuten-2'-yl)isatin from Chaetomium globosum. Isatin has also been found to be a component of coal tar. Isatin (2,3-dioxindole) is an endogenous compound identified in humans, and its effect has been studied in a variety of systems. Biological properties of isatin include a range of actions in the brain and offer protection against certain types of infections. Isatin has anxiogenic, sedative, anticonvulsant activities and acts as a potent antagonist on atrial natriuretic peptide receptors in vitro ${ }^{12-15}$. A series of p-substituted Isatin semicarbazones have shown anticonvulsant activity in MES, scPTZ and scSTY tests. Various isatin-N-Mannich bases of isatin-3-thiosemicarbazones have shown antiviral and tuberculostatic activity ${ }^{10-12-15}$.

\section{MATERIAL AND METHODOLOGY}

\section{1. Scheme I. Synthesis of 1H-indole-2,3-dione (Isatin)}

A mixture of Indole, NBS, And Anhyd. DMSO was taken in clean and dry 3-necked R.B. flask and stirred for $60{ }^{\circ} \mathrm{C}$ for 6 hours and then above $80{ }^{\circ} \mathrm{C}$ for 16 hour s under reduced pressure. After the completion of reaction the mixture was poured into water and extracted by using dichloromethaneand extacts is dried over $\mathrm{MgSO}_{4}$ and purified by silica gel chromatography with DCM as $(20 \times 3)$ eluent M.P. $202^{\circ} \mathrm{C}$.
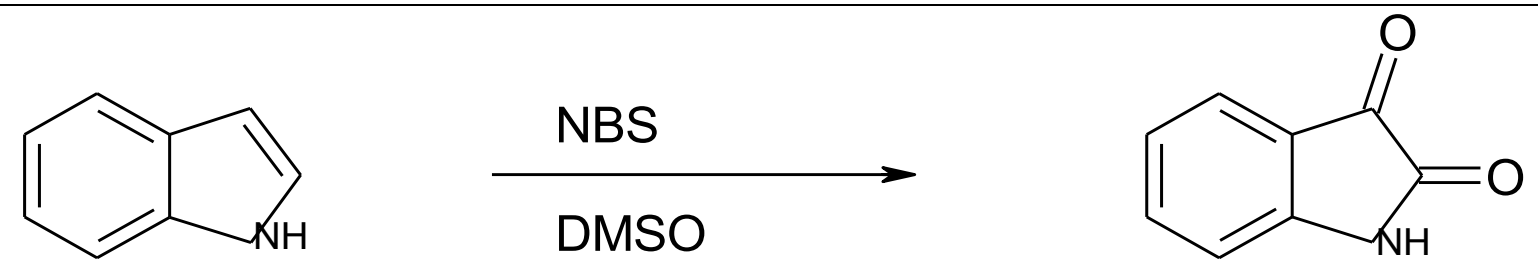

Scheme I. Synthesis of 1H-indole-2,3-dione (Isatin).

The reaction proceed by adding a solution of Isatin, con. $\mathrm{H}_{2} \mathrm{SO}_{4}$ dropwise to a solution of at 0 to $5{ }^{\circ} \mathrm{C}$ over a time period of 1 hours, produced 5-nitroisatin. M.P. 249-250 ${ }^{\circ} \mathrm{C}$. 

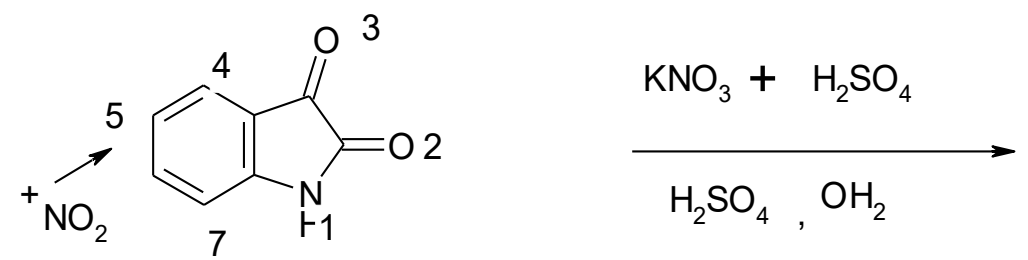<smiles>O=C1Nc2ccc([N+](=O)[O-])cc2C1=O</smiles>

(Temp. $0-5^{\circ} \mathrm{C}$ )

Scheme II. Synthesis of 5-nitro-1H-indole-2,3-dione.

\section{Scheme III. Synthesis of 2- methylquinoline-4-carboxylic acid}

2-methylquinoline-4-carboxylic acids are usually obtained by the Pfitzinger reaction i.e.by heating a mixture of isatin with acetone in the presence of alkali $\mathrm{KOH}$ or $\mathrm{NaOH}$. The mixture of isatin with a solution of $\mathrm{NaOH}$ stirred and then acetone was added and refluxed for 8 hours and then neutralizes to $\mathrm{pH} \mathrm{5-6}$ and precipitate is washed and then crystallise from methanol. M.P. $239-241^{\circ} \mathrm{C}$.

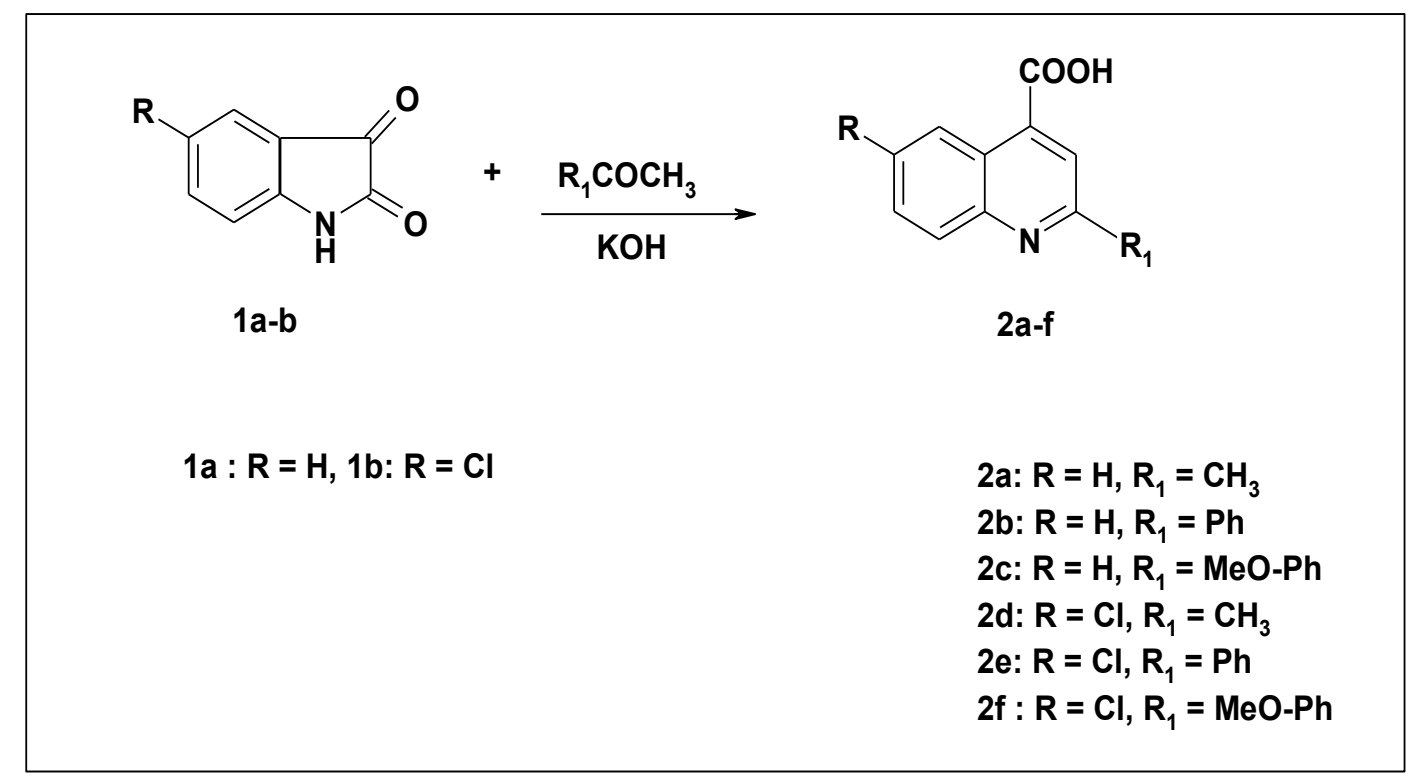

Scheme III. Synthesis of 2-methylquinoline-4-carboxylic acid.

\section{RESULTS}

1H-indole-2,3-dione (Isatin): IR (KBr): $3207 \mathrm{~cm}^{-1}(-\mathrm{NH}), 1743.4 \mathrm{~cm}^{-1}$ and 1691.12 $\mathrm{cm}^{-1}(\mathrm{C}=\mathrm{O}), 1294.83 \mathrm{~cm}^{-1}$ ( C-N stretching), $1457.97 \mathrm{~cm}^{-1}(\mathrm{C}=\mathrm{C}), 1097.25 \& 1073.06 \mathrm{~cm}^{-1}$ (C-O stretching), below $900 \mathrm{~cm}^{-1}$ benzenoid ring. $\mathrm{MS} \mathrm{m} / \mathrm{z}(\%)=147.2\left(\mathrm{M}^{+} 40\right), 119.0(100)$, 105.0(2), 90.0(70), 77.0(8), 65.0(40), 52.0(12), 43.0(12) (Fig. 2, 4). 
5-nitro-1H-indole-2,3-dione: $\mathbf{M} / \mathbf{S} \mathbf{~ m} / \mathbf{z}(\%)=193.0\left(\mathrm{M}^{+}\right.$60) $, 119.0(10), 105.0(10)$, 90.0(40.0), 77.0(10), 65.0(20), 52.0(5.0), 46.0(5) (Fig. 3).

2-methylquinoline-4-carboxylic acid: ${ }^{1} \mathrm{H}$ NMR $\delta p p m-3.0\left(\mathrm{~s}, 3 \mathrm{H}, \mathrm{CH}_{3}\right), 2.5(\mathrm{~s}, 1 \mathrm{H}$, $\mathrm{CH}), 7.90(\mathrm{~d}, 1 \mathrm{H}), 8.10(\mathrm{~d}, 1 \mathrm{H}) 8.319-,8.347(\mathrm{dd}, 1 \mathrm{H}), 8.639-8.667(\mathrm{dd}, 1 \mathrm{H})$ the peak at 10.90 which were $\mathrm{D}_{2} \mathrm{O}$ exchangeable (Fig. 1).

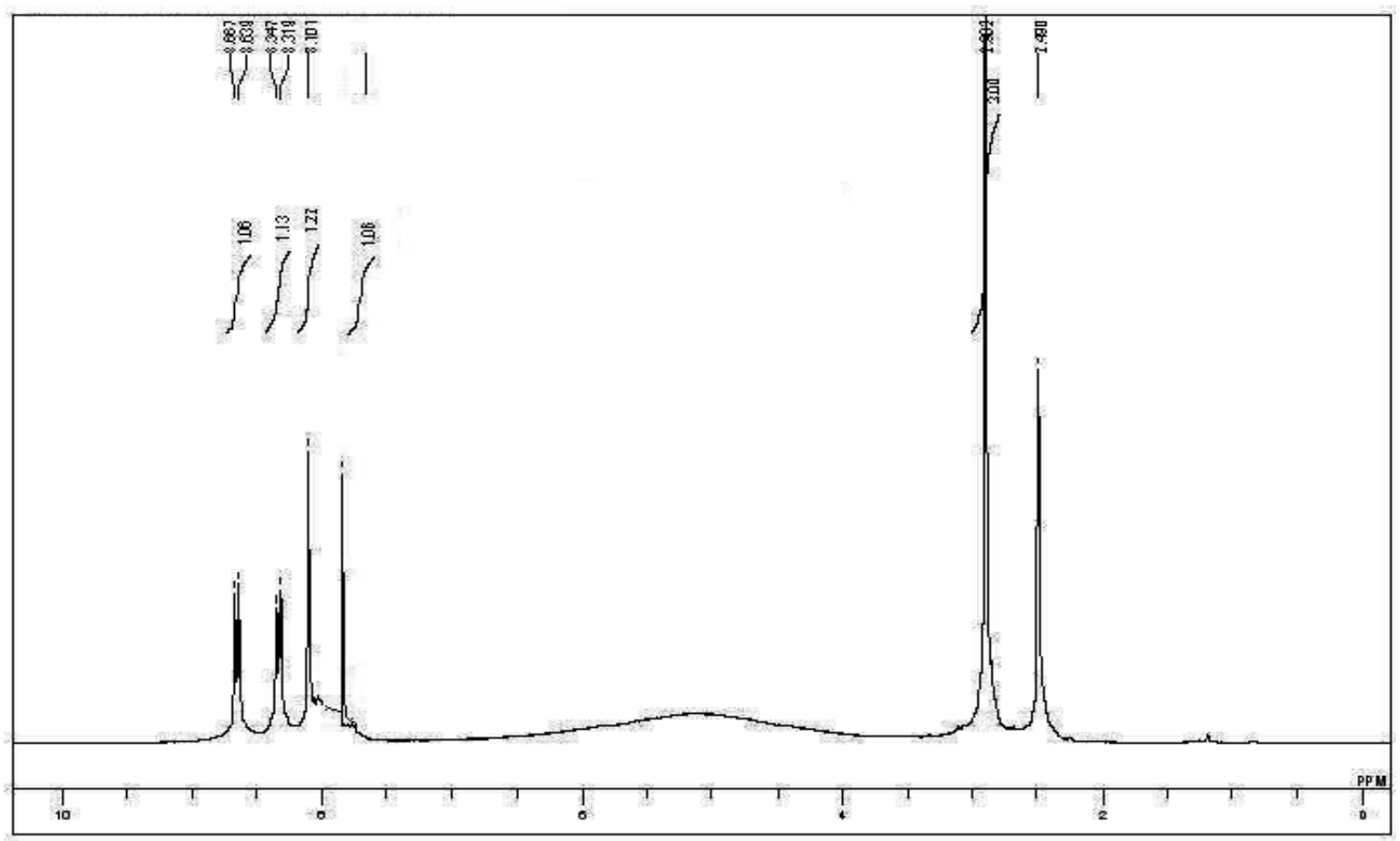

Fig. 1. ${ }^{1} \mathrm{H}$ NMR of 2-methylquinoline-4-carboxylic acid.

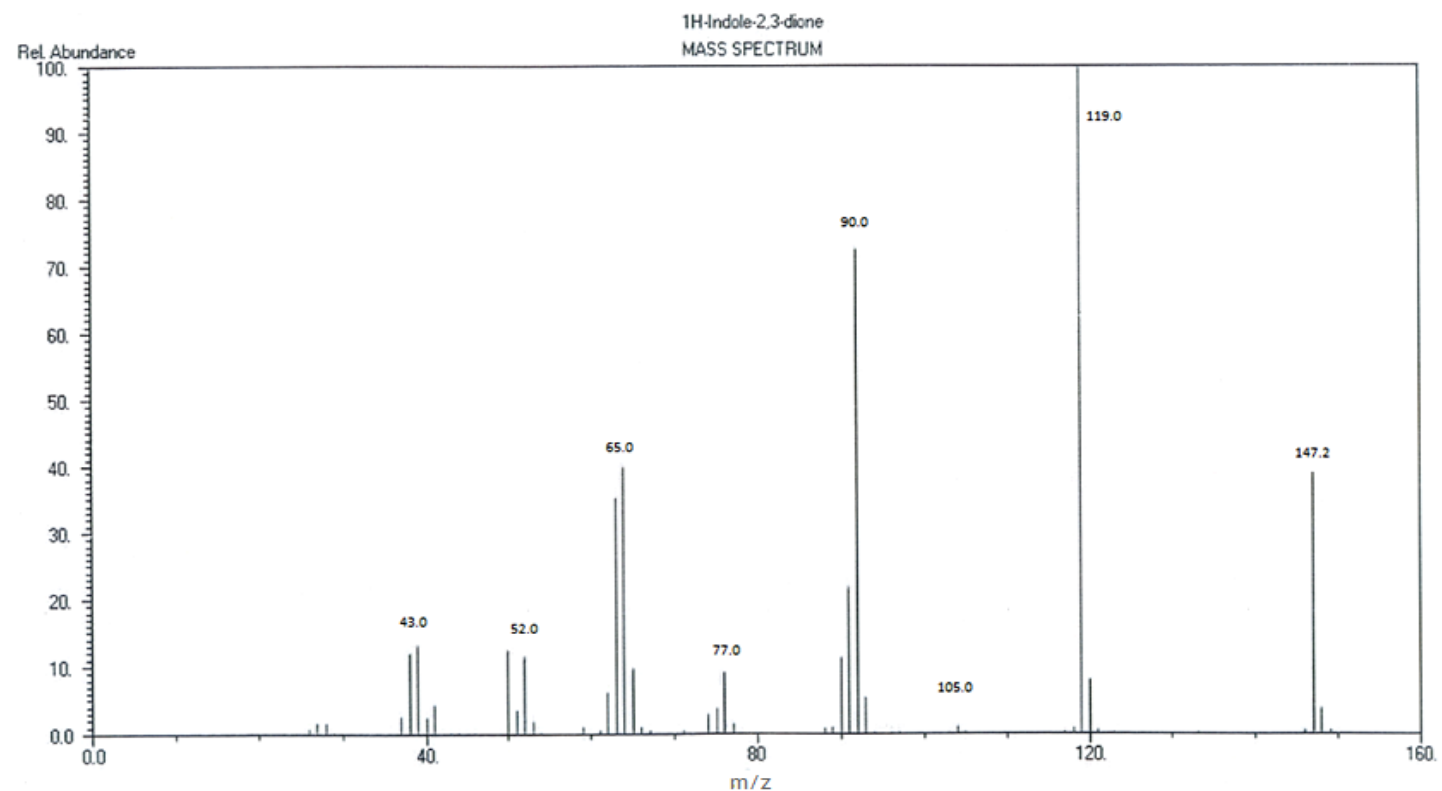

Fig. 2. Mass Spectra of 1H-indole-2,3-dione (Isatin). 


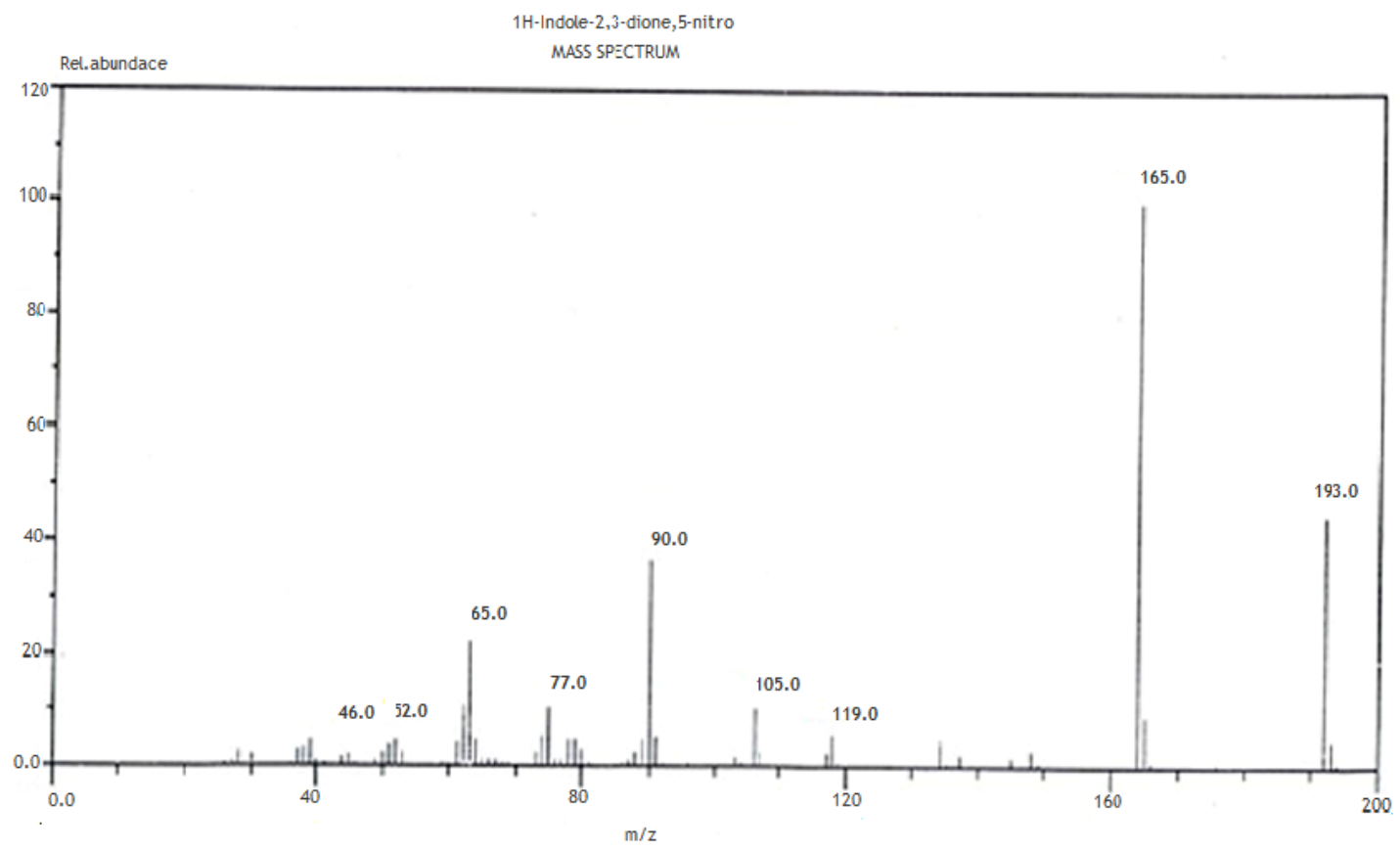

Fig. 3. Mass Spectra of 5-nitro-1H-indole-2,3-dione.

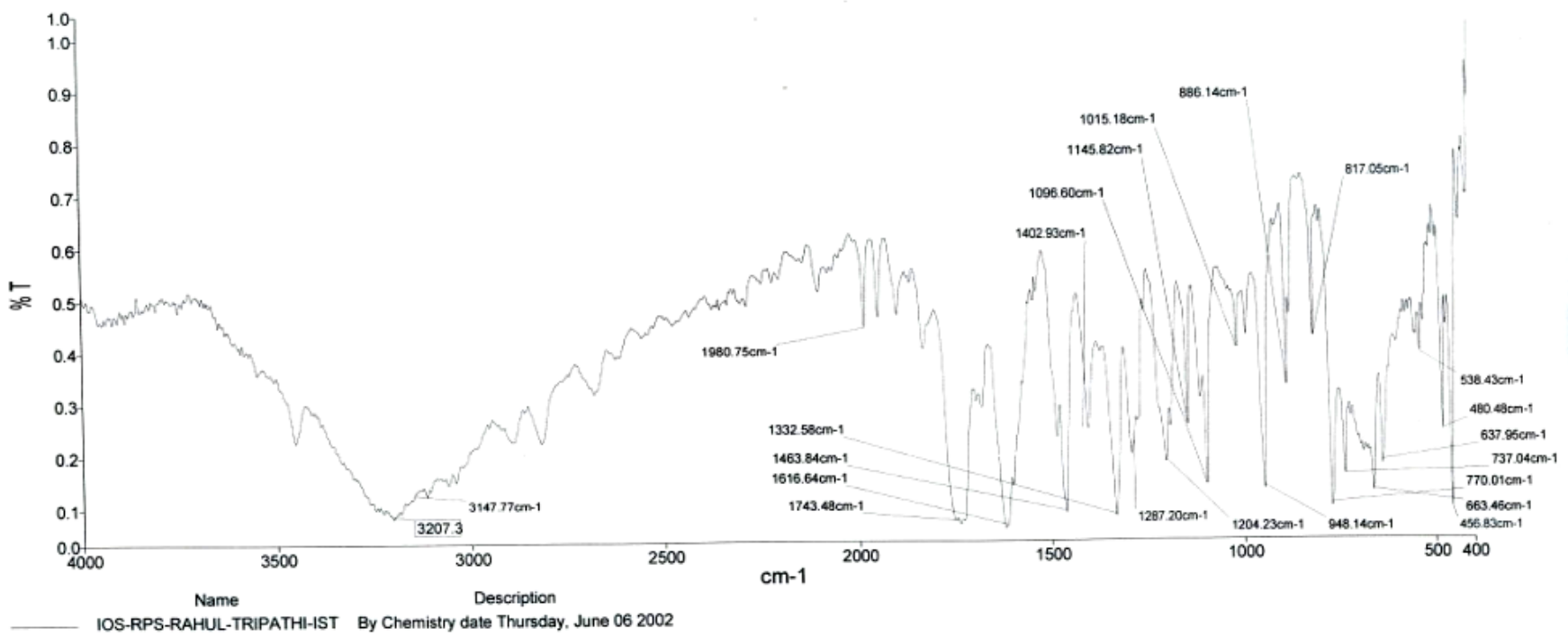

Fig. 4. INFRARED SPECTRA of 1H-indole-2,3-dione. 


\section{CONCLUSION}

We have report the sythesis of $1 \mathrm{H}$-indole-2,3-dione (Isatin), 5-nitro-1H-indole-2,3dione, 2-methyl-4-quinoline carboxylic acid. They can be further modified for the research purpose. These compound in turn can be used to synthesize various heterocyclic Compound which may have promising biological activity.

\section{References}

[1] E. Abele, R. Abele, O. Dzenibs, Chemistry of Hetrocylic Compounds 39 (2003) 1.

[2] E. G. Mesropyan, G. B. Ambrtsumyan, A. A. Avetisyan, Russian Journal Org. Chem. 39(8) (2003) 1130.

[3] M. N. Zemtsova, P. L. Trakhtenborg, Russian Journal Org. Chem. 38 (2003) 1803.

[4] Zh. P. Bespalova, A. E. Lipkin, Khim.-Farm. Zh., 1970, p. 24.

[5] R. S. Belen'kaya, A. E. Lipkin,V. M. Ostryakov, Khim.-Farm. Zh., 1972, p. 13.

[6] T. Ujiie, Chem. Pharm. Bull. 14 (1966) 461.

[7] W. Pfitzinger, J. Prakt. Chem. 33(2) (1886) 100.

[8] R. Elderfield (editor), Heterocyclic Compounds [in Russian], IL, Moscow 1954, Vol. 3, p. 164.

[9] R. Elderfield (editor), Heterocyclic Compounds [in Russian], IL, Moscow 1955, Vol. 4, p. 36 .

[10] Isatin and its Derivatives [in Russian], Shtiintsa, Kishinev 1977, p. 228.

[11] F. D. Popp, Adv. Heterocycl. Chem. 18 (1975) 2.

[12] Joaquime F. M. da Silva, Simon J .Garden, Angelo C. Pinto, Journal of the Brazilian Chemical Society 12(3) (2001) 273-324.

[13] J. Tatsungi, K. Ikuma, Y. Izawa, Tetrahedron Lett. 36 (1995) 8611.

[14] J. Tatsungi, K. Ikuma, Y. Izawa, Heterocycles 43 (1966) 7.

[15] J. Tatsungi, T. Hara, Y. Izawa, Chem. Let. (1977) 177.

[16] J. Xue, Y. Zhang, X-I. Wang, H. K. Fun, J-H. Xu, Org. Lett. 2 (2000) 2538.

[17] V. Nair, K. C. Sheela, N. P. Rath, Chem. Lett. (2000) 980.

[18] D. A. Klumpp, K. Y. Yeung, G. K. S. Prakash, G. A. Olah, J. Org. Chem. 63 (1998) 4481.

[19] P. Hewawasam, M. Erway, Tetrahedron Lett. 39 (1998) 3981.

[20] S. J. Garden, J. C. Torres, A. A. Ferreira, R. B. Silva, A. C. Pinto, Tetrahedron Lett. 38 (1977) 1501.

[22] J. Tatsungi, Y. Izawa, Synth. Commun. 28 (1988) 859. 
[23] V. J. Traynelis, W. C. Hergenvother, J. Org. Chem. 29 (1964) 221.

[24] V. J. Traynelis, W. C. Hergenvother, J. Org. Chem. Soc. 86 (1964) 298.

[25] P. G. Gassmen, Jr. B. W. Cue, T-Y. Luth, J. Org. Chem. 42 (1977) 1344. 